\title{
1. Introduction: consultants and academics in competition
}

\section{EMPTY RHETORIC OR QUESTIONABLE RESEARCH?}

Sometimes we need advice. Say you are a member of a works council and the CEO wants your advice about a reorganization project that will cost many colleagues' jobs. Is it really necessary? The works council does not have the requisite expertise, so you need help from an adviser. After all, these are your colleagues and you have a responsibility to treat the issue with care. A consultant can help to articulate and legitimize your views towards your colleagues and towards your CEO. Or you are the CEO of an international airport and think growth is in order, but you are aware of some negative effects. Can they be managed? What are their sizes? Will the positive effects outweigh the negative? You need help to answer these questions in order to legitimize your decision. Or you are a minister and want to make public transport (distribution of electricity, the delivery of post) more market competitive. What degree of liberalization is appropriate? What steps are needed to introduce liberalization? What conditions have to be monitored? Often the questions that require advice are so complex, the consequences so big and the interests involved so different that careful deliberation is needed. Consultants and academic advisers both offer their services in such situations, but which should you ask? Who can give you the guidance you need? Who has enough authority to legitimize your views? Who can inform you most adequately? Who can help you to decide in the midst of many dilemmas? Who can give you the confidence you need? And who can best challenge your views? In the end you need to make your own decisions, but with an adviser you hope you are better prepared.

Academics have a strong reputation regarding theoretical knowledge and quality of research. They claim they can provide clients with useful theory that may help them reach their ends. Consultants do not have this reputation and are even treated with suspicion by academics. For example, Fincham $(1999$, p. 341) cites the characterization that a consultant is 'the guy who borrows your watch to tell you what time it is'. Bloomfield and 
Danieli (1995, p.39) mention in their discussion that: 'consultants are charlatans . . . they simply tell organizations what they already know'. Van Aken (2001, p. 314) argues that consultants should develop a 'body of knowledge' to free themselves from the accusation of charlatanism. Clark and Salaman (1996, p.85) characterize consultants as 'witch doctors'. Alvesson and Johansson (2002, p.229) write that academics criticize consultants for lack of deep knowledge, for being shallow, overpaid and immoral, and even for causing major corporate problems. Economists like Goodwin (1988), Peacock (1992) and Thornton and Ward (1999, p. 104) characterize the consultant as a 'hired gun' as opposed to the neutral, independent academic expert. These characterizations are supported in research by Van Dalen and Klamer, who compare the authority of consultants with academic economists in a questionnaire answered by 478 Dutch economists, 58 percent of them working for universities and business schools, the others for governments (14 percent) and in business (24 percent). The authority of academics is ranked highest, above foreign policy institutes. Consultants are positioned at the bottom of the ranking (van Dalen and Klamer, 1996, pp. 261, 265, 270). Academic respondents rank consultants lowest. However, they are not the only ones who are critical. Consultants like Ashford (1998), Argyris (2000), Pinault (2000), de Sonnaville (2005) or Ardon (2009) make jokes about their colleagues, they challenge them or are self-critical. However, they do not show disdain like academics do. Armbrüster (2006, p. 5) characterizes this academic view as critical, sometimes even showing the distaste of the academic community.

Consultants respond to these academics. Czarniawska and Mazza (2003, p. 277) cite consultants who claim that 'Academics are only able to talk; we do the real stuff! That's what we are paid for.' Some academics agree. Clark and Majone (1985, p.6) argue that academic advice often lacks relevance: 'For in practice, scientific inquiry cannot discover most of the things that policymakers would like to know.' Frey and Eichenberger (1993, p. 192) expect the relevance of European economics for the economy to continue to decrease in the near future. International academic journals publish 'institution-unspecific research' and no research about local or national economic questions. More recently Frey (2006, p. 307) claims that 'economists in their scientific capacity should be careful about making claims about the influence of economics on the economy'.

Academics such as Kieser (2002) and van Baalen (2001) are interested in the phenomenon that academics show disdain for their competitors but at the same time are outperformed by them in competition on economic assignments. Economists consider the price of a service an indicator for the economic value of that service. They rely heavily on money as an 
indicator of value, but are resistant to measuring their own services in these terms (Cordes et al., 1993, pp.461-5; Friedman, 1986, p. 8; Kieser, 2002, pp. 220-1). Academic advisers are paid less than consultants for the same service. How can that be?

In Critical Consulting, edited by Timothy Clark and Robin Fincham (2002), consultants' advice is considered a discipline that has to be taken more seriously as an object of research because the academic community does not really understand what consultants are doing. Consultants gained the attention of academics with the growth of their business in the 1990s. The great riddle for many academics is how it is possible that consultant knowledge seems flawed and superficial from an academic perspective, but influential and well accepted enough for clients to pay for it (Kieser, 2002, p. 212; Salaman, 2002, p. 249). Academics wonder how consultants can do so well (Armbrüster, 2006, p.41; McKenna, 2006, p. 7). That academics should outperform consultants due to their research abilities is the implicit assumption of the critical academic view. And since that does not happen when academics do contract research, should we formulate the hypothesis that consultants are better researchers?

In Management Consulting, edited by Matthias Kipping and Lars Engwall (2002), several contributions show that: 'consultants have managed to establish themselves as "legitimate" knowledge carriers in addition to, and in competition with, academia' (Engwall and Kipping, 2002 , p. 13). One indication of their strong competitive position is that consultants are more cited than academics in Manager Magazine, one of the major German periodicals for managers (Faust, 2002, p. 159). This proposition is also supported in a case study by Engwall et al. (2002), who show that the Swedish professor Rhenman with an academic consultancy (SIAR) could not combine academic standards with a competitive market proposition. His consultancy became like others, due to market pressure. Some academics therefore start to question academic methodology owing to the problems they experience when applying academic knowledge (Alvesson and Johansson, 2002, p.230; Argyris, 1996, p. 393; van Baalen, 2001, p. 70; Berglund and Werr, 2000, p. 652; ten Bos, 2001, p. 45; Kieser, 2002, p. 222; Salaman, 2002, p. 251; Weggeman, 2001, pp. 112-15). They question their secluded position, their distrust of personal experience, their lack of interest in practical relevance and their preoccupation with timeless, value-free knowledge and general universal principles.

Few academics have explored whether consultants are better researchers, or if academic advisers can improve their research methods by learning from consultants. On the contrary, a popular academic solution claims that consultants are only successful by their empty rhetoric. Salaman (2002, p.250) refers to the characterization that 'consultants 
trade in performance and empty rhetoric'. Clark (1995) argues their success depends on impression management. This includes the suits they wear, their PowerPoint presentations, their image, and so on. Fincham (1999, p. 338) also refers to this view in which 'the sheer force of rhetoric is emphasized'. Though consultants say nothing new, they say it so nicely that most clients are satisfied and even motivated to carry on with consultants. Rhetoric makes the difference, and academics should not be associated with that practice: 'they should be distinguishable from consultants' (Kieser, 1997, p.70). This interpretation of rhetoric comes close to the popular accusation of charlatanism. In The Expansion of Management Knowledge, edited by Sahlin-Andersson and Engwall (2002), Ernst and Kieser (2002, pp.69-71) even argue that managers become 'addicted' to consultants, which implies they have a low opinion of managers as well.

Academics who conclude that consultants are successful only by their empty rhetoric seem to abandon their own norms of a serious and profound study when they start to analyse the work of consultants from a rhetorical perspective. Their analysis excludes differences in the use of arguments and in the use of knowledge, which should be part of a more serious rhetorical analysis of the riddle. Even Clegg, et al. (2004b, p. 36, 2004b) who consider consulting a 'discursive practice' without disdain, do not analyse consulting as a rhetorical phenomenon. Clark also argues that rhetoric is important for consultants. He is considered the main proponent of a rhetorical view on consulting (Sturdy et al., 2009, p. 7). His analysis is of a general type though. He does not consider rhetoric as something academics have to deal with as well, as something with different faces and with a relation to content. Berglund and Werr (2000) explore the kind of consultant rhetoric in more detail, and also in contrast to academic rhetoric. Cordes et al. (1993, p.476) and Klamer (2007, p. 171) have provided an example of a content-based rhetorical analysis, with attention to arguments. They have analysed why politicians do not adopt the economic terminology of their academic advisers, claiming that politicians and consulting economists are divided by a rhetorical gap. This is different from valuing the rhetoric of politicians as empty and the rhetoric of academics as meaningful. These authors have analysed rhetorical differences rather than impede the discussion with the simplistic "solution" of some academics that consultants are successful on the basis of their empty rhetoric.

This book investigates rhetorical differences between consultants and academics. It contributes to the debate on consulting by showing what consultants and academic advisers do with their words in the context of advice, and how they use them. A related objective is to contribute to a deeper understanding of advice practices, based on what advice is derived from: specific words and arguments spoken to clients with real demands. 
The analysis does not assume that "empty" rhetoric explains consultants' success, but intends to unravel the rhetorical nuances that make the difference. Compared to consultant advice, advice by academics is discussed even less and their superiority is only assumed, based on their critical attitude towards consultants. To compare both characters as competitors is new. The book also contributes to rhetorical analysis in a social-economic context by offering a detailed investigation of the argumentation practices of consultants and academic advisers involved in advice assignments.

\section{ACADEMIC ADVISERS OUTPERFORMED IN COMPETITION WITH CONSULTANTS}

Academics concerned with the suitability of their methodology in the context of practical economic and management advice are not alone. Since the early 1980s the issue of the relevance and use of academic knowledge has occupied policy makers in the Netherlands. Academics have been pressured by the government to offer advice by means of contract research. The expertise available at universities should help solve technological, economic and social problems. Economists and management scientists must leave their ivory towers to help clients just as consultants do. Academics are thus challenged to demonstrate the usefulness and applicability of their knowledge.

In the early 1980s contract research contributed less than 10 percent to the total income of Dutch universities (Overlegcommissie Verkenningen, 1996, p. 26). More recently it has risen to 15 percent of their income or 750 million euros in 2004, almost 30 percent of the budget for all research activities of all Dutch universities (VSNU, 2006). It is reasonable to expect that economic faculties, which in the Netherlands include departments for business administration, earn about 30 percent with contract research. For technical faculties the share may be higher, for the humanities possibly lower. Exact figures are hard to obtain.

The growth of academic contract research is an indication that academic advisers do well, but compared to the performance of consultants their success is less convincing. The consulting market grew about 19 percent each year in the late 1990s, which is more than twice as fast as the growth of contract research by universities. The volume of the Dutch consultant market was about 1.4 billion euros in 2000 (Twijnstra et al., 2002, pp. 32, 40). Issues that belong to (business) economic disciplines, including business administration, dominate the market for advice. Less dominant branches of advice are communication, information technology (IT) consulting and other more technical issues that belong to management 


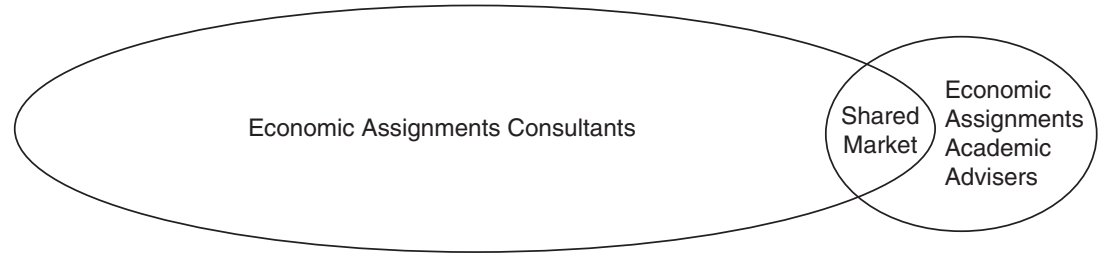

Figure 1.1 Academic advisers and consultants on the Dutch market for economic advice

consulting. IT consulting is growing rapidly, however, and has even acquired traditional management consultancies in recent years (Kipping, 2002, p. 38).

Since the Dutch consultant market in general exceeds that of academic contract research, and since the share of economic consulting as part of all management consulting exceeds the share of economic contract research as part of all contract research, we can conclude that consultants dominate the Dutch market for economic advice. There is also a shared market, where both consultants and academics work on similar assignments for similar clients (Figure 1.1).

Van Hoesel and de Koning (2005, p. 121) estimate the total market of policy research at 300 million euros. Universities' market share is 10 percent; consultancies and firms specializing in policy research have 80 percent. They also distinguish other small suppliers. Since Van Hoesel and de Koning count a part of the research by universities in the group of specialized firms on policy research, the share of university research is somewhat larger, say 15 percent compared to consultancies' 75 percent. These "educated guesses" are for the period shortly before 2005 although the authors do not mention which year. It is likely that these shares approximate the market shares for economic advice.

Academic advisers and consultants sometimes serve the same clients or win the same kind of assignments. Differences between consultants and academics can be identified most clearly here because different assignments require different approaches. On this shared market of economic assignments (Figure 1.1) are questions such as whether Amsterdam Airport should grow, or to what extent and under what conditions should the electricity market be liberalized. There are also clients that ask both consultants and academic advisers for advice, such as the Ministry of Economic Affairs. It is thus possible to neutralize subject and client influences by comparing the style of advice. We can study rhetorical differences between consultants and academic advisers by means of text analysis of the reports 
written for similar clients on similar questions. These conditions have led me to formulate the following research question:

In advising on economic questions, what differences in argumentation account for the market success of consultants versus academic advisers?

The consultants and academics I distinguish between have a degree in economics or a related academic discipline. The difference is that consultants work for private consulting companies such as Berenschot, Accenture or McKinsey whereas academic advisers work at universities as full-time researchers or as academics who sometimes participate in contract research. In my comparison the institution defines the role. For those who combine roles, if they write that their role is as a consultant for a consultancy, I consider them consultants. If they work on an assignment for clients in the context of academic contract research, I consider them as academic advisers.

Because the comparison is between consultants and academic advisers, my research does not apply to assignments with a strong repetitive character, such as implementation of business models or IT systems. A characterization that fits this kind of management consultant is the 'creative' consultant (Visscher, 2001, p. 69) or the research consultant who aims at advice. Their advice has little to do with 'routine' (Feltmann 2001, p.133). Creative or research consultants often answer questions where a repetitive practice falls short or when questions are relatively unique. The big consulting firms involved in implementation try to standardize their consulting practice (Bolweg, 2001, p. 192). Limiting my focus to creative or research consulting excludes many assignments of management consultants: on those markets they do not compete with academics.

Though the academic adviser and the consultant are the main characters in my comparison, there are variations within these characters. Not all academics work as advisers. Many do not, actually. These pure academics cannot be classified as academic advisers; they are different characters. They do not write for clients but by their own initiative publish on self-defined questions, or are involved in teaching. Pure academics can, however, serve as a point of reference for academic advisers. It is likely that pure academics influence the attitude and professional values of academic advisers, since the status of pure academics is high at universities. The academic adviser character must devote a serious amount of time to contract research. Like pure academics, they can also lecture, hold seminars and publish in academic journals. Some are successful in both kinds of research.

Another character is the "hybrid" who is both consultant and academic. Hybrids can, for example, work three or four days as economic 
consultants and one or two days as professors at a economic (business) or business administration department. Other examples are academics with consulting experiences or consultants with a $\mathrm{PhD}$. The hybrid can write a report as a consultant, but be an academic as well. In theory it is also possible that they write a report as a contract researcher while also being a consultant. This possibility is somewhat theoretical though. Hybrids combining the role of academic adviser and consultant are rare. Most combine consulting with teaching or with writing academic publications.

It is likely that the hybrid is looking for opportunities to connect both roles, or to learn from consultants as an academic or to learn from academics as a consultant. Argyris and Schön are well-known examples of this hybrid character. There are more examples of a successful combination of both roles. Weggeman mentions leading academics and successful consultants such as Fayol, Sloan, D'aveni, Davenport, Ghoshal, Hamal, Porter, Prahalad, Senge and Tichy. He also cites intense cooperation between universities and consulting firms such as Stanford and MIT in the USA (Weggeman, 2001, p. 108). He argues that it is not necessary for the academic and consultant worlds to be so different and that they can benefit from each other. The question is if the competitive relationship is a Dutch, a European or even a more general phenomenon. Khurana (2007, pp. 305-12) describes similar developments towards academic specialization and an increasing lack of practical relevance at US business schools, which make characters like Porter still positive exceptions. Similar developments are reported from Sweden (Engwall, et al., 2002). Although there may be more positive exceptions in the USA, the overall picture resembles the Dutch situation. Recent developments towards academic specialization in the Netherlands result from the academic policy to imitate the US system.

The experiences of hybrids are an interesting source for both the academic world and consultancies since they know both worlds thoroughly. They can change roles from the academic character to the consultant character. They often publish in academic journals about the consulting discipline. In these journals they compete "as academics" with the pure academics who write about consultants. These hybrids do not have personal experience with academic advice though; as consultants they compete with academic advisers on the shared market of economic assignments.

\section{DISCIPLINES RELATED TO ECONOMIC ADVICE}

University economists specialize in an economic subdiscipline in research and teaching, such as microeconomics, economic marketing, industrial economics or internal organization. Consultants will identify less with 
Table 1.1 Actors and their different positions in the consulting process

\begin{tabular}{|c|c|c|c|}
\hline Clients & $\begin{array}{l}\text { External } \\
\text { consultants }\end{array}$ & Academic advisers & Academic disciplines \\
\hline $\begin{array}{l}\text { Managers } \\
\text { Policy makers } \\
\text { Internal } \\
\quad \text { consultants }\end{array}$ & $\begin{array}{l}\text { Management } \\
\text { consultant } \\
\text { Marketing } \\
\text { consultant } \\
\text { Policy researcher }\end{array}$ & $\begin{array}{l}\text { Management } \\
\text { scientist } \\
\text { Marketing scientist } \\
\text { Business economist } \\
\text { Industrial } \\
\text { economist } \\
\text { Institutional } \\
\text { economist } \\
\text { Welfare economist } \\
\text { Macroeconomist } \\
\text { Microeconomist }\end{array}$ & $\begin{array}{l}\text { Management } \\
\text { sciences } \\
\text { Marketing science } \\
\text { Business economics } \\
\text { Industrial } \\
\text { economics } \\
\text { Institutional } \\
\text { economics } \\
\text { Welfare economics } \\
\text { Macroeconomics } \\
\text { Microeconomics }\end{array}$ \\
\hline $\begin{array}{l}\text { Influences on } \\
\text { consultants/ } \\
\text { academics } \\
\text { by interests/ } \\
\text { assignments }\end{array}$ & \multicolumn{2}{|c|}{$\begin{array}{l}\text { Interaction of influences on } \\
\text { the market for advice }\end{array}$} & $\begin{array}{l}\text { Influences on } \\
\text { consultants and } \\
\text { academics by } \\
\text { ethos within } \\
\text { discipline }\end{array}$ \\
\hline
\end{tabular}

these academic specializations. However, there are many of them, some are interdisciplinary to some degree, such as institutional economics or organization studies, with more or less economic legacy. As consultants are less specialized than academics, their clients are usually even less familiar with the disciplines relevant to economic assignments.

Table 1.1 presents the main actors on the market for advice on economic (business) questions, starting on the left with clients and ending with examples of pure academic disciplines on the right. Consultants and academic advisers are positioned in the middle of the table. The table suggests that clients are closer to consultants and will thus have more influence on them than on academic advisers: the latter remain more in their discipline than consultants. Similarly academic disciplines are closer to academic advisers and will have more influence on academic advisers than on consultants.

The distinction between clients/managers, consultants and academics is made by van Baalen (2001, p. 54) from a Dutch perspective and by Kieser (2002, p. 206) from a German perspective. Neither distinguishes between academic advisers and pure academics, but Weggeman (2001) does. $\mathrm{He}$ leaves out the group of clients/managers and compares consultants, academics providing services and academics providing scientific work. 
Van Balen and Kieser mention differences between consultants and academics in terms of social relations that influence their work. Weggeman (2001, pp. 103-5) argues that although academic advisers and consultants are in the same position providing a service to clients, their client relationship is different: academic advisers work according to their own scientific methods like an indifferent supplier. Consultants work in a more dependent way with their clients. Compared to clients, consultants and academic advisers both have a more reflective position, but are not as reflective as pure academics. Consultants are more involved with clients whereas academic advisers are more reflective and are inspired by discussions in academic disciplines.

Academic advisers asked to give advice on economic (business) issues often belong to a department of the faculty of economics or business administration. These faculties are organized in departments along the lines of academic subdisciplines such as those in Table 1.1. However, it is hard to translate all subdisciplines in economic departments. Some, such as institutional economics or transaction-cost economics, come close to schools, such as neoclassical economics. Economics in this book is understood quite broadly, including social science interdisciplines with a strong economic component such as management studies, organization science, economic sociology, institutional economics and so on. Frey and Eichenberger (1997, p. 38) go as fas as to expect that economics as it was understood traditionally will 'flourish in other faculties' due to current trends like specialization and mathematization within economic faculties. Augier et al. (2005, p. 88) have documented the increasing importance of economics in organization science for example. This causes a language problem: what is meant by economics? This book follows the broad definition of economics meant as the counterpart of economic (business) questions posed by clients in contrast to a more narrow neoclassical view. This includes simple neoclassical economics, especially in assignments about liberalization of markets, but not exclusively so. The question of whether a large national airport should grow is considered as economical as well.

Economic subdisciplines can differ a lot. They are characterized by a body of literature, specific journals, preferred research methods, and even different epistemological and ontological assumptions. The field of management sciences or organization studies, for example, uses more qualitative research methods such as case study research or narrative analysis while marketing research favors more statistical analysis. Micro- or neoclassical macroeconomists prefer economic modeling and mathematics to build their models and they often rely more on "stylized facts" than on direct observations.

Reputation within one subdiscipline is the most important goal of 
academics (Frey and Eichenberger, 1993, pp.191-2; Overlegcommissie Verkenningen, 1996, p. 19). Specialization within a subdiscipline is necessary for an academic career (Bergeijk et al., 1997, p.4). Disciplines and subdisciplines thus develop without much contact. Could we therefore expect that consultants have a more homogeneous character and that there are more differences between academic advisers due to the stronger influence of economic subdisciplines?

\section{THEORETICAL AND PRACTICAL KNOWLEDGE}

Consultant knowledge is more embedded in common sense discussions, close to the knowledge clients refer to, whereas academics are more embedded in the discussions of their discipline (Kieser, 2002, p. 212). At the same time, the work of consultants is better accepted than academic contract research by "practitioners" like managers or policy makers, according to indicators such as market share and market value. Academic responses to this phenomenon vary from surprise to hostility towards consultants. Many academics judge the work of consultants by their own academic standards, and their judgment is devastating. Other academics start to question their own methodology. They argue that one should investigate consultant approaches in more detail. Little research is done, however, to analyse how academic advisers perform in competition with consultants when they serve the same clients.

Philosophy has a long tradition of discussing different forms of knowledge. Theoretical knowledge as produced at universities is not the only kind of knowledge. Practical decision making regarding what to do this evening, how to organize your life or what present to buy for a friend is hardly in need of scientific knowledge. These decisions are based on knowledge though. We apply the knowledge about our friends to decide what present will suit them. Could the knowledge orientation of consultants and academic advisers contribute to explaining the hostility between consultants and academic advisers?

Aristotle (1985, p.1140a) differentiates between theoretical knowledge and practical knowledge (phronesis). These forms of knowledge are complementary. Practical knowledge is based on experience and allows us to cope with changing realities. Theoretical knowledge investigates the stable, unchanging part of reality. Theoretical knowledge remains valid for a long time, whereas practical knowledge loses relevance if the situation changes and the knowledge has to be renewed. Aristotle argues that we need to argue and deliberate to make sense of practical situations. We cannot refer to universal and general scientific knowledge if a situation 
is changing. In The Uses of Argument, Toulmin (1994) refers to this view of Aristotle, arguing that the orientation of scientists and logicians is too general to make sense of argumentation in practice.

More recently Polyani (1967, p.4) has introduced the concept of tacit knowledge to explain that 'we can know more than we can tell'. We can recognize somebody, but we cannot explain why. We can recognize someone's mood, but we have difficulty explaining by what signs we know it. Therefore humans seem to be able to know and learn more than can be expressed in the explicit terms of science.

Bourdieu (2002, p. 3) stresses the differences between theoretical knowledge and practical knowledge in a different way, claiming that it requires a theory of practice to reflect on the way objective or scientific theory influences practices. One has to shift the focus to practices to analyse theoretical practices vis-à-vis other practices. From the perspective of practices Bourdieu (2002, p. 123) argues that different fields of practice have their own universes of meaning, which often obey a 'fuzzy logic of approximation'. He claims that agents socialized within these different practices make use of more than the classical five senses:

The sense of necessity and the sense of duty, the sense of direction and the sense of reality, the sense of balance and the sense of beauty, common sense and the sense of the sacred, tactical sense and the sense of responsibility, business sense and the sense of propriety, the sense of humour and the sense of absurdity, moral sense and the sense of practicality, and so on. (Bourdieu, 2002, p. 124)

Bourdieu thus argues in line with Polyani that we know more than what we can learn from our five senses. The results of our other senses are needed to perform well in non-scientific practices. Similar arguments are made by Weinberg (1972, p. 213) who claims that many question are transscientific, meaning they are unanswerable by science, or by Habermas (1988a, pp. 38-45) who distinguishes between five different domains of knowledge, where the domain of theoretical knowledge refers to academic knowledge and the domain of aesthetic knowledge to matters of fashion, local social practices and cultures.

These general philosophical distinctions might apply to consultants, since consultants with philosophical backgrounds like Argyris and Schön have wondered what consultants do or should do in order to be effective. They stress the specific characteristics of thinking in the context of practice. Argyris stresses that theories have to be simple and sound to be applicable in practice. They should not be dependent on too many conditions and manipulation of these conditions should be part of the theory. Although Argyris (1996, p. 403) admits that scientific models can be helpful in organizing thoughts, they are often not useful in practice: 
'The unhelpfulness came when I attempted to apply the models to creating behavior. The model is well beyond the complexity that the human mind/brain can cope with.' Argyris argues that the attention necessary to understand scientific models or theory interrupts the 'flow' that belongs to action in the context of practice.

Schön has also criticized the applicability and relevance of textbook knowledge in the context of practice. He introduced the concept of the reflective practitioner to overcome the crises of confidence in professional knowledge. Professional knowledge is in the book; it is general and can be taught, although in the context of practice the result of this knowledge is professional incompetence: 'the situations of practice are characterized by unique events' (Schön, 1983, p. 16). This 'unique case calls for an art of practice' (Schön, 1983, p. 17). Argyris (2000, p. 6) argues likewise by stressing that professionals suffer under 'skilled incompetence'. Their focus is on knowledge generated in the past, in experimental situations, and it prevents professionals from seeing what is happening now. The criticism by Argyris and Schön might apply to both academic advisers and consultants, but one could expect that consultants take theoretical knowledge less seriously, and that they are more involved in the practical way of applying knowledge. The "art of practice" addressed by Schön is learnable, and with this claim Schön paraphrases Polyani by arguing that we can learn more than we can tell or write down.

The philosophical clues presented above open an academic perspective to consider the practice of consultants compared to the practice of academic advisers. Apparently not all academics agree with the common prejudice that consultant knowledge is 'flawed, fashionable, glib and at odds with expert, scientific academic knowledge' (Salaman, 2002, p. 250). From a philosophical point of view one can expect that consultant knowledge is at odds with scientific academic knowledge, but not because it is flawed. That criticism is made too easily. Consultant knowledge is different from academic knowledge, but not necessarily inferior.

\section{RIGOR AND RELEVANCE}

The comparison of consultants and academic advisers also relates to the rigor and relevance debate as discussed in the Academy of Management Journal (2001, 50 (4), 2005, 48 (6), 2007, 44 (2). The idea is that academics pay more attention to the rigor of their findings, whereas consultants consider relevance more important. In this debate many scholars agree with the criticism made by Thomas and Tymon (1982) that academic research often lacks relevance. They describe five criteria important for practitioners 
such as managers and consultants. Research should better describe phenomena relevant to the practitioner by increasing external validity. The investigated phenomena should be recognizable in the context of practice (descriptive relevance). Research should be instrumental: it should be related to the goals of the practitioner (goal relevance). Research should be operational. Practitioners should have control over the independent variables (operational validity). Findings should be new, they should add to common knowledge (non-obviousness) and they should be there in time (timeliness). Academic research too often does not meet these criteria. Could that explain the lower market value of academics? Not necessarily, since academics defend the rigor of their methods. Rigor is a precondition for relevance, one could argue. Lack of rigor could thus undermine the relevance of consultant research. Or are there also problems with the rigor of academic research? Argyris (1996), for example, argues that if causal relations do not apply to the context of the practitioner, or if he cannot control the conditions, the research not only lacks relevance, but lacks rigor as well. This criticism relates to operational validity.

The common criticism is that scientific knowledge should become more relevant to society and to practitioners (van Aken, 2004; Gulati, 2007; Rynes and Shapiro, 2005; Rynes et al., 2001; Tsang, 1997). Khurana (2007, p. 345) shows how American business schools try to develop a good value proposition for their students based on scientific knowledge, and measured in terms of the salaries their students can earn later in their career. The original objective was to train managers, but in the 1980s a growing number of those with MBAs were starting as consultants (Khurana 2007, p. 328). Similarly Augier et al. (2005, p. 92) argue that organization studies at American business schools strive towards relevance of research, in opposition to the more disciplinary fields such as psychology, sociology or economics at universities. In the last decades they were able to increase academic recognition, at least within the interdisciplinary field of organization studies. However, at the cost of relevance: 'gaining recognition in the academic reputation system became the main emphasis' (van Aken 2004, p. 222).

The criticism of timeliness is central. Consultants, for example, take weeks or months on their projects: they aim at timeliness, whereas academics are used to a much longer time horizon (Allen, 1977; Auerbach, 1992, p. 239; van Aken 2004, p.238). Academics take more time to read about relevant theoretical developments in order to be rigorous. They strive to be credited for being reliable, honest and learned, in accordance with a tradition of centuries that has shaped their professional ethos.

Most reflections on the rigor relevance gap are theoretical, or based on anecdotal evidence (Rynes et al., 2001, p. 341). There is a need for more 
empirical research of an inductive kind in order to discuss hidden assumptions behind the work of academics and practitioners like consultants. Rynes et al. (2001, p. 349) argue that this kind of research may help to make tacit knowledge explicit. By comparing argumentation strategies of academic advisers and consultants when they give advice, this book contributes to an understanding of consultant use of theory compared to academic use, and how they both integrate theory in their arguments. It opens up possibilities to reflect on the different kinds of rigor, preferred by consultants and academics while helping their clients make the right decision, assuming that there is at least some relevance in this comparison: a client pays for the service.

\section{PRELIMINARY EXPECTATIONS ABOUT THE PRACTICE OF BOTH PROFESSIONS}

Consultants have developed their profession in the market from the start. Although it is criticized if consulting is a true profession with shared professional standards (Khurana, 2007), many still talk about it as a profession, and even a quite successful one with growing dominance (McKenna, 2006). Their ethos is the product of many experiences with many assignments. They follow the demand of the market in a way they consider most appropriate for their clients in the long run. Part of their expertise, however, is the result of their academic education; they are able to integrate the academic elements they consider valuable in practice. But their focus is to respond to client demands in a way that best serves the client. What they learned at university is not the primary orientation.

Academic advisers have a background that is mainly rooted in the academy. Krugman $(1995$, p. 7$)$ characterizes academic advisers as 'the professors' and consultants as 'policy entrepreneurs' (p.10). The professors are working for clients like the entrepreneurs: 'A professor can try to play entrepreneur - after all, the rewards in both money and a sense of importance can be huge. Ultimately, however, she is at a disadvantage, because she is too constrained by her obscure professorly ethics' (p.12). Krugman thus argues that academic rules and habits give academic advisers strong guidance in their work. For that reason I consider academic advisers a profession as well, without assuming beforehand that both professions really earn this label.

Because academic advisers not only believe in their professorly ethics, but also disdain the style of consultants, we could expect that they would not integrate consultant elements in their practice. Academic advisers work as knowledge providers, and they guarantee that this knowledge is 
based on academic research methods and theoretical knowledge. That is their strength, and they distinguish themselves from consultants this way: a differentiation strategy.

It could be perilous for academic advisers to imitate consultants because their consulting experiences are not commensurate with consultants' knowledge by experience. Consultants also have had an academic education, but academic advisers have had no training in consulting - safer for them to remain in academia. They hardly know what consultants do, so they can hardly imitate them successfully.

We should thus expect academic advisers to stay close to their own ethos and strengths. The service of academic advisers would then be more independent, more critical and less sympathetic towards their clients. This expectation leaves room for an optimistic and even romantic explanation of why academic advice has a lower money value. The arts market manifests similarly. Popular music serves the demands of the market better than classical music, but who would measure the worth of classical music in terms of its money value? Like the arts, academic advisers could feel superior as suppliers of classical music compared to consultants as suppliers of popular music. It would even suggest a more homogeneous character of consultants compared to academic advisers. How can we examine these expectations in more detail?

\section{THE BENEFITS OF A RHETORICAL ANALYSIS}

Doing research is a human project, but there is a long tradition of suspicion towards the human elements in science. Plato and Aristotle were critical about personal elements in discussions. The force of an argument, not the personal characteristics of an author, should persuade; the argument by authority is thus avoided. Van Eemeren and Grootendorst (1992, p. 161) discuss this argument under the heading of fallacies, showing little respect for personal expertise. Today most mainstream social scientists prefer the positivist rhetoric of impersonal objectivity. It is only acceptable to use experiences as inspiration for research. If experiences are used to justify claims that pretend to some extent to be valid, they are considered problematic (Popper, 2002, p. 5), since experiences lack objectivity.

However, a growing number of policy scientists, organization theorists and even some economists argue that positivism excludes valuable personal knowledge from science, such as values, experiences and opinions (McCloskey, 1983, p. 510). They consider the claim that economists can be truly objective in a positivistic sense to be flawed. McCloskey says about the economic discipline: 'Humanists dislike it for its baggage of 
antihumanist methodology. The scientists dislike it because it does not in reality attain the rigor that its methodology claims to achieve' (McCloskey, 1983, p. 513).

Experiences and personal valuations matter in economic research as they do in economic reality. McCloskey (1983, p. 513) explicitly refers to the possible improvements of science by means of integrating humanistic elements such as personal experience, introspection or common sense. Exclusion of experiences as a source of information means exclusion of an important part of the subject of economics and the subject of economic advice as well. Advice is not only based on instrumental scientific arguments about how to reach goals, but also on other elements of talk and conversation (Alvesson, 1993, p. 1007; Clark, 1995; Clegg et al., 2004a, p.36). A rhetorical analysis can acknowledge all knowledge elements as subject of analysis by its humanist methodology since rhetoric studies all means of persuasion. Analysis of these means of persuasion is relevant in the context of giving advice: we are unsure of what to do if we ask for advice, and need good arguments or good legitimization to decide.

The first argument in favor of a rhetorical analysis, therefore, is that giving advice demands arguments. Advice is about appropriate future action in a personal, social, economic or political context. There is no certain knowledge about complex future situations; advice always has to be supported. This motivation requires deliberative inquiry and in the end sound or convincing arguments for legitimization. In this context, a hard proof or a big truth concerning future situations is impossible. It is even more difficult to deliberate about action in the future than to argue that some action happened in the past, as lawyers and judges have to do. The degree of certainty a consultant can offer in his claims is therefore different from the degree of certainty scientists aim at. Consultants do not have the time for this degree of certainty. Companies would miss their chances and new policies would be too late with this approach. The alternative is deliberation, finding good arguments and rhetorical talent to generate convincing advice. Since a consultant cannot offer certainty, the bottom line is that advice should be well supported. If the subject under investigation is obviously a rhetorical practice of argumentation and deliberation, rhetorical analysis is the most promising way to uncover that practice. Toulmin (1994) offers a framework to analyse argumentation in more detail and guides me in this analysis, along with authors who have applied or enriched his analytical framework. Rhetorical analysis also helps me distinguish between different kinds of arguments, such as the argument by cause, argument by authority or a motivational argument, which is based on attractiveness or desirability. These analytical distinctions help reveal how consultants and academic advisers use and back these arguments in their advice. 
The second and related reason to apply a rhetorical analysis is that a traditional scientific analysis seems to ignore or disapprove of normative discussions about what actions or decisions are better or worse in a social and economic context. In deliberations about a future course of action normative or motivational arguments can have a strong convincing power. Traditional positive scientific methodologies lack the conceptual language to discuss these normative issues. A rhetorical analysis can investigate them.

The third argument is that economic advice often requires research approaches that do not meet the standards of traditional scientific censorship. This experience-based knowledge, these rough estimations and these expert guesses give necessary indications to formulate advice. Consultants prefer interviews and group discussions to identify and discuss possible conflicts in values, preferences and interests, to collect relevant experiences, or to test tentative estimations or expert guesses. Consultant approaches require personal contact, involvement and a kind of compassion. These accounts of knowledge do not fit well into a traditional academic investigation. They get labels such as unscientific, fashionable and flawed, which imply a disapproval of pre- or trans-scientific knowledge. Pre-scientific and scientific grounds and claims can both be analysed from a rhetorical perspective as long as they are part of an argument or means of persuasion. Therefore my analytical perspective to investigate differences in practice between consultants and academic advisers is rhetorical.

The fourth argument to apply a rhetorical analysis of advice practices is that the comparison between academic advisers and consultants should be impartial. This objective is problematic, since there is a communication gap between consultants and academic advisers. The rhetoric of academics is hardly able to generate an understanding about what consultants do. Accusations and questions for better understanding dominate academic contributions to the debate. Klamer (2007, p. 154) would characterize this as the 'stupidity problem'. Academics cannot respect what consultants do, and consultants cannot take seriously what academic advisers do. It seems that the rhetorical gap results in dividing academics from consultants. A rhetorical analysis can subsume the communication problem in its investigation.

\section{RESEARCH DESIGN}

The views about consultants in the academic literature are diverse: academic self-esteem and skepticism regarding academic advice compete with each other. In addition there is no clear academic view about what advice 
should be, or how it should be practiced. Given the different views about the character of academic advice and consulting, explorative research seems most appropriate to investigate the rhetorical differences between the advice practices of consultants and academic advisers in more detail. Case study research is one way to do explorative research.

My research design is based on triangulation, which is a common research strategy in case study research (Eisenhardt, 1989, p. 538; Yin, 2003, pp. 14, 98-99). Triangulation means using different data sources or different theoretical perspectives to offer insight into the same phenomenon. Data triangulation in this book is based on views on advice practices of consultants and academic advisers expressed in books and articles written by consultants and academics as a first kind of source, compared with accounts of these advice practices in advice reports. Overlap between the results based on these different data sources indicates that the results are more reliable.

The conclusions from case study research can be generally valid by means of 'analytic generalization' according to Yin (2003, p. 32). A case study should be based on theoretical research to establish general claims or propositions that can be explored in the cases. In this book general claims about consultants and academic advisers are partly based on academic theory on advice and advice roles distinguished by consultants (Chapter 2 ), and partly on reflections on consultants' and academic advisers' practices (Chapter 4). These reflections are derived from academic researchers' statements about consultants and academic advisers, and practitioners' statements about their own experiences in the academic literature and practitioner books. The kind of books and articles used for this review are characterized at the start of Chapter 4 . The analysis of the literature explores the espoused argumentation style of consultants compared to academic advisers and their preferred research and advice approaches. The analysis will reveal the professional ethos of consultants and academic advisers regarding their use of arguments in advice. The Toulmin's framework to explore these argumentation styles is presented in Chapter 3.

The results from the literature review serve as a general starting point for an in-depth argumentation analysis of 20 reports divided equally between two economic debates in which consultants and academic advisers give advice about growth of Amsterdam Airport (Chapter 5) or liberalization of the electricity market (Chapter 6). The reports that I use as data are described and introduced before each of the case descriptions. At that point I also elaborate on how the reports were analysed. Reports written by consultants and academic advisers are the sources used to analyse their contribution to the debates. The reports show how consultants and academic advisers argue in practice, and what research approaches they 
carry out. Frey (2006, p. 304) claims that case study research is a fruitful approach to analyse 'how and to what extent economics and economists influence the economy', a closely related question.

The two economic policy debates were selected because they had more than five advice reports written by academic advisers and by consultants over a period of about ten years, criteria which were difficult to fulfill. Therefore only major public debates were appropriate. Within these debates the representativeness of the reports is high, especially on the academic side. In most debates I considered for selection there were too little academic reports. For each report how the advice is supported and how these contributions convince are analysed. The double case study design enables me to compare the results of both cases by cross-case analysis, which enables a more general interpretation of the results. The question is whether academic advisers and consultants do in practice what they say in their reflections on their practice, and if their ethos is thus reflected in their advice reports. Words and deeds do not always match, even if the deeds the written reports - consist of words again.

The two main sources of knowledge, advice reports and literature about advice practices, suffice to back my conclusions within an academic context. However I feel free to refer to some of my experiences as a third source of knowledge. My experiences will have an influence on my position in the debate about consulting and academic advice, but they cannot legitimize conclusions without the support of the two other sources. They mainly help awareness of flaws in my theoretical discussions along the way. My experience tells me, for example, that empty rhetoric by consultants is the exception instead of the rule. I cannot rely on that experience as an indication of some general truth, but it makes me aware of generalizations in the academic literature that were made too fast.

The outcomes of my analysis are therefore to some extent "experience proof". The proof means that my analysis does not conflict with my personal experiences, even though these experiences cover a mere fraction of the research domain. I consider it in any case a valuable addition to academic methodology. Though experiences or personal observations can be biased and harm the objectivity of the results, my suspicion of experiencefree knowledge overrides the risk. It is the moment where the consultant within me starts to criticize academic habits. Consultants consider experiences necessary to legitimize advice. They are usually not sufficient grounds due to their local validity, but they are necessary to take personal responsibility for recommendations.

Finally, I have to make a confession. The consultant report of KPMG Bureau voor Economische Argumentatie (1998) in the liberalization debate, analysed in Chapter 6 , is the result of a project under my super- 
vision. It is a risk for my objectivity in the sense that I could have difficulties in criticizing this report like the others. Due to the time passed that has I feel a great distance to the report. It is also only one report out of ten consultant reports, so it cannot influence the outcome that much and it has not been a reason for selecting the debate. It is a coincidence. The bigger risk for my integrity could be that I have been a consultant for six years. On the other hand, I work as an academic now, so my current loyalty is academic and only my research interest concerns the field of consulting. For this interest I consider it an advantage that I know one of the debates from the inside and that I have experienced consulting practice as well.

\section{OUTLINE OF THE ARGUMENT}

The previous sections show that in certain cases academic advisers and consultants work under the same conditions: they work on similar assignments for similar clients. That opens up the possibility of comparing the consulting practices of both groups. Such a comparison could reveal what the professions do differently and why clients are willing to pay consultants more for their services. The relevance of these research questions is acknowledged by Salaman, who argues that when consultant advice is relevant to senior executives, the work by consultants is relevant to academics as well (Salaman, 2002, pp. 250-51).

Answering these research questions will help to investigate whether the quality of academic advice can be improved. To do so, it will be necessary to analyse the criteria that academics and consultants use to judge their own work. It is not my purpose to use the criteria of one profession to judge the other profession. That approach is good for jokes and accusations. Consultants will not meet criteria of universal validity; academic advisers will not meet criteria of immediate practical relevance. A clear understanding of the differences in professional criteria is necessary, however, if one wishes to investigate the possibility of cross-fertilization between the two professions. Any recommendation made to academic advisers must result in improvements that can be judged as such by academics.

The focus in this investigation is on differences in advice argumentation and the professional legitimization of these differences. How do consultants convince their clients? How do academic advisers? What kind of claims do they make, and what kind of arguments do they use? What kind of knowledge do they integrate in their arguments and what kind of questions do they accept? Since I intend to make recommendations as an academic to academic advisers, my approach should be in line with my own recommendations. The proof will be in the pudding. I will, therefore, 


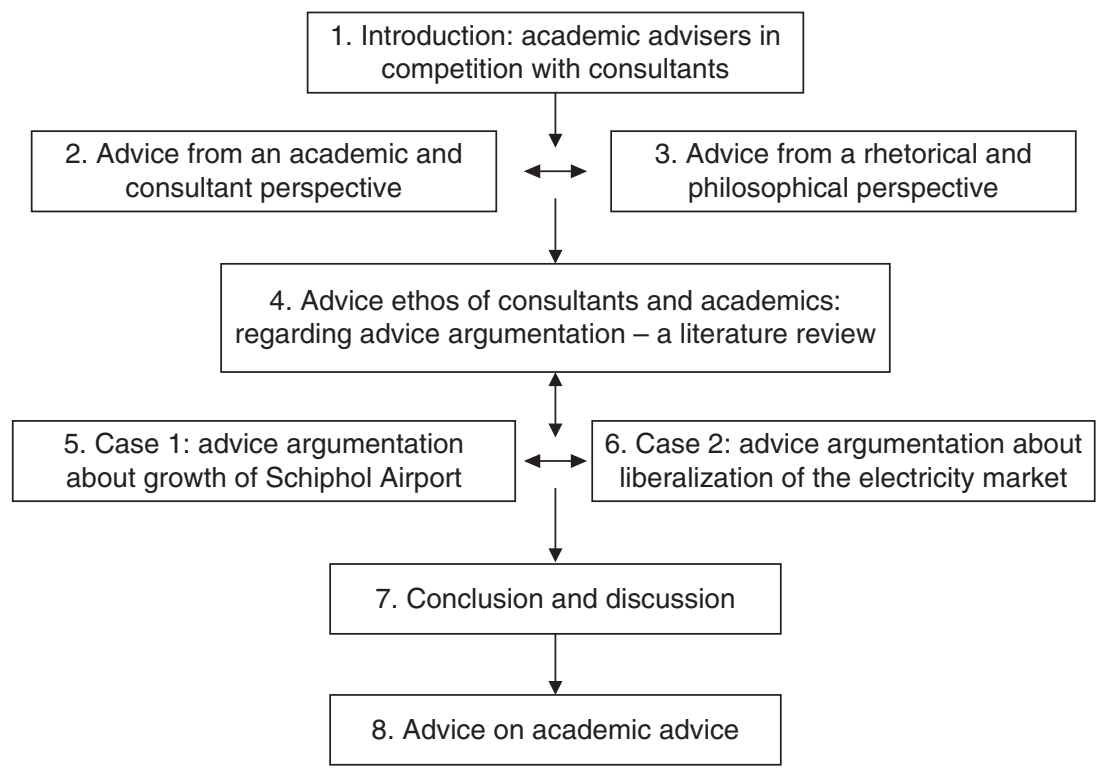

Figure 1.2 Line of argument in outline

not conclude with advice 'in private' as traditional academic economists suggest (Robbins 1952, p. 150; Hennipman, 1977, p. 89), but I will make explicit how my analysis and my advice in the last chapter are connected during my argument, which is briefly summarized below.

A discussion about the nature of advice will be the starting point of my analysis in Chapters 2 and 3. Consulting economists define advice differently from philosophers and language scientists. Economists consider economic advice a scientific, instrumental and value-free enterprise. Philosophers and language scientists stress the deliberative and normative aspects in advice and decision making. They also argue that giving advice is a speech act. Since the rhetorical practices of consultants and academic advisers will be analysed, my understanding of economic advice will be inspired by philosophers, philosophical minded social scientists and language scientists.

Since it is my intention to take both professions seriously, I will continue my analysis in Chapter 4 with a characterization of the ideal types of academic advisers and consultants according to academics and consultants themselves. Consultants, for example, consider the relationship with their clients as very important. They will maintain this relationship 'at all costs' (Ashford, 1998, p. 101), since for them it is the most important 
precondition for the acceptance of any kind of advice, critical or not. Academics appreciate a distant, independent relationship and are critical of the consultant-client relationship because it implies too much dependence. These differences translate to the way both professions make their argument.

After this analysis of consultant and academic ethos I analyse the differences in practice to see if both professions meet their own criteria, or even some criteria of the other profession. That is the purpose of the report analysis in Chapters 5 and 6 . The outline of the argument is summarized in Figure 1.2. A double pointed arrow indicates that the chapters have to reconfirm each other, an indication of triangulation in the research design.

Chapter 7 concludes the research by comparing differences in argumentation practices between both professions and across the two cases. The chapter will also show that consultants act more in accordance with their ethos than academic advisers. Academic advisers come close to consultants in some respects, but their adapted approach still differs from the consultant approach. Their adaptations are so fundamental that it is problematic that they still pretend to work according to their academic ethos.

In the last chapter the academic adviser in me is challenged most extremely: what can I recommend in the end after so much research? What are the implications of the current practices for clients? Can the academic discipline claim advice as one of its provinces? How should it be conceptualized and performed? It is a test in itself. 